Journal of Jungian Scholarly Studies

Vol. 2, No. 2, 2006

\title{
Synchronicity in the 21st Century
}

\author{
Helene Shulman Lorenz, Ph.D.
}

Pacifica Graduate Institute

We now have an opportunity to bring to bear on the topic of synchronicity over forty years of interdisciplinary work in the sciences and humanities that have occurred since C. G. Jung died. One of the reasons Freud's work has been so much more read and accepted in American universities than Jung's, is that Freud's work was more consistent with mainstream medical, scientific, and cultural assumptions of the 20th century than Jung's. In fact we know that Jung's life and work were attacked as by many as cult-like, mystical, unscientific, and even psychotic. This caused many practitioners who were interested in Jungian psychology to ignore the topic of synchronicity, and develop only the clinical implications of his work. Under these conditions, Jungian work and Freudian work began to converge in practice as others have noted (see, for instance, Homans 1995, or YoungEisendrath 1997). Yet, in this narrower interpretation of Jungian psychology, we lose some of the most dramatic, profound, and challenging implications of his work. I would like to suggest that now we are in an epoch when new theory in the sciences and the humanities makes it possible to link some of Jung's most radical ideas, particularly those connected to synchronicity, with contemporary work going on in diverse fields in the 21 st century. In this paper, I hope to explore five questions about synchronicity:

1. What characterizes experiences of synchronicity?

2. What were the experiences and thoughts of Jung and the first generations of Jungians in connection with synchronicity?

3. What light could the new sciences of chaos or complexity theory throw on the topic?

4. What recent interdisciplinary work might help to understand synchronicity in new ways?

5. What questions might Jung's work on synchronicity suggest for our own contemporary sensibilities?

First a definition: Jung's theories about synchronicity are one way of thinking about a long list of human experiences that have been documented throughout the ages, connected with precognition, prophetic dreams, divination, and other uncanny 
coincidences. In these experiences, one event becomes linked with another in a way that we do not expect and couldn't predict rationally based on evidence. The moment of insight may seem like a release into an imaginative and visionary state that transcends the normal rules of space and time. It is sometimes felt as numinous, ecstatic, or filled with the greatest meaning for life. Often such experiences are connected with highly emotional concerns like death, birth, or marriage, but sometimes as well, an unexplained coincidence simply happens and one doesn't know why or what it means and it remains a puzzle.

These experiences are what Jung and Aniela Jaffe called psychic facts (CW 8 par. 625). That is, it doesn't matter if other people believe that these events happened or that they can be documented or somehow proved to be true. The key issue is that they appear within the experiences of individuals who are deeply impressed with them. How we explain them afterwards, how we theorize about them, depends to a large extent on the local cultural context in which they appear. In various cultures the experiences are related to ancestors, gods and goddesses, orishas, oracles, or a divine order. In our culture, they are for the most part either anomalies that we cannot explain, are discounted, or are taken as a sign of mental illness and given a diagnosis of schizophrenia, psychosis, or perhaps, borderline personality disorder. Jung understood them as part of the phenomenology of spirit.

Some typical examples of synchronicity are given in Aniela Jaffe's book, Apparitions and Precognition. One case from the work of Louisa Rhine is based on a waking vision:

A weaver looked up from his work one day and saw the apparition of his dead mother in a corner of the room. She beckoned to him and he got up and went towards her. At that moment a heavy piece of machinery broke loose and crashed into the wall, hitting exactly the spot where he had been standing a few seconds before. (31)

Other cases are based on dreams:

A woman dreamt that she was standing on a bridge and saw a man struggling desperately for his life in the water. The same evening she received news that her father had been drowned. (22)

A girl in Solothurn (Switzerland) dreamt that she met her cousin on the Bahnhofbrucke in Zurich. The cousin told her that their grandmother had died. In the morning she received the announcement of the death. (22)

Sometimes the link is made through sounds, as in this story of a haunted house:

The rapping was heard by several people in both houses for years, and always in autumn; but the icy wind was felt only at our house. We then learned by chance that many years before, when the 


\section{Lorenz}

house was not a Home but a block of flats, a young man had shot himself in what later became the housekeeper's room. The ghost disappeared completely after we had all prayed many times, and never returned even in later years. (128)

I became interested in the topic of synchronicity during my analytical training in Zurich when I began to have many precognitive dreams of my own. These events created a kind of individuation crisis for me, in which I had on one side, a set of impressive experiences, and on the other side, an inherited theoretical picture of the world that held no place for such experiences. I felt myself stretched across a gap that held a tension of opposites, just as Jung had predicted a confrontation with the unconscious might produce.

However, during the ten years from 1985 to 1995 that I was struggling with these issues, a profound shift was taking place at the edges of the scientific and academic worlds, where more powerful computers, a new set of theoretical questions, and ever deepening intercultural encounters as a result of globalization, were giving birth to paradigm changes. As I began to search for ways to rethink my understanding of the world, vast new areas of relevant research opened up, causing a crisis of competing paradigms. Here was a kind of synchronistic experience between my personal crisis of theory and what has been called the "culture wars" in the academic world. I could see my immediate experience being mirrored in the world. This mirroring between self, community, and world can be part of the individuation process, allowing insight into what Jung called the "Unus Mundus" or unified world, in his last work, Mysterium Coniunctionis and which Marie Louise von Franz described brilliantly in her book, Projection and Recollection in Jungian Psychology. As a result of my own need for integration, I began a process of research into these new paradigms that eventually became a thesis at the Jung Institute, later my book Living at the Edge of Chaos: Complex Systems in Culture and Psyche.

In the academic world, research on synchronicity is generally thought of as part of the study of "altered states of consciousness." Of course, we only think of such states as "altered" if we take as a norm an Enlightenment model of a private conscious mind separate from a public Newtonian world of cause and effect. An overview of the areas of research connected with "altered states" encompasses an impressive diversity of studies. A new field of Consciousness Studies explores differences between communities with generally monophasic consciousness like the scientific establishment, that view the normal waking state as the only source of knowledge, and communities with polyphasic consciousness where dream, trance, and other altered states are also considered meaningful. Such studies explore the many religious, ritual, and healing practices that seek to induce altered states of 
consciousness through dance, meditation, and chanting that may lead to trance, possession states, or ecstatic encounters. There are world-wide practices of entering into such states for the purposes of divination -- that is, of knowing the future in advance-- and many technologies of divination, like the Tarot and the I Ching, that are very popular in the United States today. Synchronicity is also connected to imaginative systems in which people feel themselves to have spiritual guides, with foreknowledge of events that may be animals, gurus, dream figures, or daimons. Apart from Jung, Rumi, Socrates, Black Elk, and Joan of Arc would be famous examples of individuals who consider such altered states to be significant. Information systems research made possible by computer science, now being linked with neurobiology and the cognitive sciences, have opened up new ways of modeling consciousness as "self-organized systems" (see, for example, Maturana 1992). There is a link with mental health research beginning with Janet's work in Paris on what he saw as "hysterics" suffering an "abaissement du nivel mental" and more contemporary work on ideation in psychosis (Perry 1976). The enormously varied genre of ghost stories is related. Jung also connected the sightings of UFO's and extra-terrestrials to synchronicity (CW 10, par. 660). Recent neurological research on brain chemistry and synesthesia are related (see for example, Cytowic 1989; Robertson 2005). A historic field of parapsychology explores forms of precognition and telepathy called Psi and ESP (Beloff 1993). LSD research, during the few years in which it was legal in the United States, recorded the experiences of laboratory subjects in altered states (Grof 1998). Folk traditions of "doubling" are common in many cultures, where the actions and intentions of a family member to return home are known by relatives in advance because of sounds or signs (Jaffe 143). Doubling of the self and elements of precognition also occur in reports of near- death and out-of-body experiences. Finally, virtually everyone has experiences of hypnogogic states, daydreams, and imagination in which alternative futures are imagined.

The crucial question, it seems to me, is whether we are talking about important and valid forms of knowledge that need to be taken into account or whether this level of experience is so unreliable that it should be dismissed. There are very profound implications to this choice. After the disaster at Chernobyl in 1986, interviews showed that large numbers of people had dreamed in advance that the plant was unsafe and a nuclear accident was imminent. If there had been space to hear these dreams and explore their meaning seriously in community, the worst nuclear catastrophe in Europe might have been avoided. Yet during the last several centuries of scientific thinking, the notion that one could know something about the future based on a dream, vision, or sensory impression has been a clear marker for mental illness rather than knowledge. 


\section{Lorenz}

Jung's interest in the topic of synchronicity was a family inheritance. As we know from his autobiography, his cousin held seances which Jung attended with his mother and later wrote about in his dissertation. In his personal life, Jung and his family had a rich encounter with synchronicity, though it would be many years before he found a name and a place for these phenomena in theory. At various times he experienced ghosts, hauntings, inexplicable sounds, and precognitive dreams that he documents in many articles and letters. Jung reports on his first meeting with Freud in Vienna in 1909 where he asked Freud what he thought about parapsychology and precognition. Freud strongly rejected the topic. Then this happened:

While Freud was going on this way I had a curious sensation. It was as if my diaphragm were made of iron and were becoming red-hot - a glowing vault. And at that moment there was such a loud report in the bookcase, which stood right next to us, that we started up in alarm, fearing the thing was going to topple over us. I said to Freud: "There is an example of a so-called catalytic exteriorization phenomenon."

"Oh come," he said: "That is sheer bosh!"

"It is not," I replied. "You are mistaken, Herr Professor. And to prove my point I now predict that in a moment there will another such loud report." Sure enough no sooner had I said the words than the same detonation went off in the bookcase.

To this day, I do not know what gave me this certainty. But I knew beyond all doubt that the report would come again. Freud only stared aghast at me. I do not know what was in his mind, or what his look meant. In any case, this incident aroused his mistrust of me, and I had the feeling that I had done something against him. I never afterward discussed the incident with him. (Jaffe 191)

It was not until the 1950's that Jung began to publish work about synchronicity. This gap of forty years represent Jung's own struggle for individuation in relation to the official knowledge of his epoch, which he called "collective consciousness." $\mathrm{He}$ began his 1951 essay this way:

In writing this paper I have, so to speak, made good a promise which for many years I lacked the courage to fulfil. The difficulties of the problem and its presentation seemed to me too great; too great the intellectual responsibility without which such a subject cannot be tackled; too inadequate in the long run, my scientific training. If I have now conquered my hesitation and at 
last come to grips with my theme, it is chiefly because my experiences of the phenomenon of synchronicity have multiplied themselves over decades. (CW 8, par. 816)

Working with Aniela Jaffe and Marie Louise von Franz, as well as Sinologist Richard Wilhelm and physicist Wolfgang Pauli, Jung and his circle began to shape the outlines of a worldview that could make a place for the phenomena of synchronicity and altered states of consciousness. Their work developed along six related avenues, that today we can see as part of a much larger paradigm change in process in Western thought.

1. Anticipating the contemporary field of Cultural Studies, they developed a critique of European culture (and by extension, American culture) as narrow, onesided and dissociative and showed how individuals were struggling against the restrictions of the collective consciousness of the period in their dreams and personal lives. The shadow of European culture was seen as dangerous and destructive, an intuition that only deepened as they watched the rise of the Nazis to power and the development of World War II.

2. Anticipating contemporary anthropological concerns, they carried on a study of comparative religions to find ideas and ritual and healing practices in other places and other times that made a place for synchronicity. They were particularly interested in Chinese Taoist texts, in Sufi and Jewish mysticism, and in alchemical studies, all of which they saw as possible models.

3. Anticipating recent neurobiological work on altered states of consciousness, they did their own research on parapsychology.

4. Anticipating complexity theory, they began to develop the idea of what has come to be called "self-organizing systems." That is, they began to understand that there are unexpected and acausal orderings that could develop out of the connectivity of numbers, so that there had to be a kind of apriori "archetype of order" at the heart of life, world, and consciousness. This would give rise to different dimensions of order, some causal (and Newtonian) and some acausal (and synchronistic). Though the computer science that would show this to be the case did not exist at the time, they understood intuitively that such a "psychoid" factor must exist.

5. Anticipating contemporary post-structuralist, deconstructionist, and crosscultural research in the humanities, they theorized that the observer is completely implicated in what is observed, and that it would be possible to show a difference between the effects of very rigid, complex-ridden, projective structures of observation and those that had undergone a process of disidentification or "withdrawal of projections" and opened more permeable boundaries to the world.

6. Anticipating recent trauma theory, they imagined the general situation of a typical European would be that of a fragmented, dissociated consciousness with 


\section{Lorenz}

major gaps in narrative. Through the instability of the splintered consciousness, new and surprising elements would be constantly trying to emerge in a process of projection or exteriorization. These energies could produce accidents, synchronicities, or dreams as attempts at emergent consciousness and healing.

Jung's ultimate conclusions about a framework for understanding synchronicity were very radical. They relativized the importance of conscious thought by placing it in contrast to a second psychic organizing system located in the body and in the world. Jung understood that his work required an extreme paradigm change:

[A] second psychic system coexisting with consciousness - no matter what qualities we suspect it of possessing - is of absolutely revolutionary significance in that it could radically alter our view of the world. (CW 8, par. 369)

In the final chapters of his last work, Mysterium Coniunctionis, completed when he was eighty years old, Jung opened out to the widest view of the problem of synchronicity. He interpreted the underground opus of alchemy to be suggesting a road map for psychological development toward a mature self-knowledge and engagement with the world, far beyond the goals of personal therapy to remove neurotic symptoms.

Developing children would naturally be shaped by the conventions and collective consciousness of their own time and location; but at some point in midlife, adults would discover gaps, blindness, contradictions and absences in their own knowledge. This first stage of alchemy, the discovery of the shadow, would require a "distressing" and "painful," "difficult" and "dangerous" "stripping off of the veils of illusion" (CW 14, par. 739). This stage can end in a refusal of the process or a retreat to what Jung calls an "aesthetic attitude" toward the psyche, leading to a fascination with all things magical at a safe and uninvolved distance.

The move to the second stage of alchemy requires a radical shift in point of view. Here one begins to realize that one is locked within an evolving system of emergent images and fantasies outside of our own control, that shape our understanding of the world. We realize that we can interact with this ideational and projective system, but our self-understanding is also formed by it. In this process, we discover that there is a second psychic system, a mysterious pre-existent center of imagination. In Sufi mysticism, many different stages of realization are charted in the discovery of imaginal worlds. But there are all sorts of dangers here as well. It is possible to become identified with this archetypal font of imagination, or with a guru who symbolizes this center, as the enormous amount of Jung's writing on the subject of inflation suggests. We might begin to imagine that we are private owners of the divine in the world. When such ideas inevitably collide with social realities, there may be panic, defense, rage, disillusionment, or a regression to the faith of childhood. What is demanded instead at this point, according to Jung, is "a new 
interpretation in accord with the spirit of the age, of the archetypes that compensate the altered situation of consciousness." (CW 14, par. 744) That is, we need to struggle to individuate by finding what is emergent in our own local environment and giving voice to it, even if the ideas we have are not conventional or popular.

The third stage of alchemy again requires a radical reorientation of understanding. Here, we discover that our knowing, as well as everything that is known in the world, is evolving within a field of relatedness and interdependence, an Unus Mundus. In a framework quite similar to ones that have developed within Process Theology, Liberation Theology, or Pure Land Buddhism, Jung imagines a human being fully humbled by the awareness of seeing "through a glass darkly," entering into life community with a simple openness to, and faith in, emergence, relatedness, and synchronicity. In the third stage of alchemy, we enter what Jung calls "the potential world of the first day of creation...coexistent and coeternal with God" (CW 14, par. 767). This is "not a fusion of the individual with his environment, or even his adaptation to it, but a mystical union (unio mystica) with the potential world" (CW 14, par. 767).

Knowing that we have been educated in a dissociated consciousness, and that this means new elements of transformation are constantly bubbling up at the edges of what we know, Jung imagines that in this third stage, we begin to place our chips on the new, the imaginative, the potential, the transformative. Nowhere in his work does Jung ever suggest that we simply leave behind our conscious, rational thought, though he believes that struggle with the unconscious will always be a "defeat of the ego" as it was before. What he seems to imagine here is that we become open to a constant remarriage between what we already understand and the new emergent elements that are coming forward in both our inner and outer worlds. In this vision, every event, every conversation, every accident, every image is seen as a meaningful coincidence that can be met with as much curiosity and compassion as the figures in our dreams. Grace, renewal, and redemption may enter the world as an incarnation of what Jung calls the "archetype of the divine child"; and instead of saying there is no room at the inn, we enact a ritual of welcome. This would mean a reorientation toward what is Other both in the world and in one's own personality.

The constant emergence of new images, symbols, and energies is evidence of a self-organizing, world constituting factor, a light of nature, a numinous creative living godhead that Jung honors through a philosophy of spontaneity. In the end, synchronicities prove to be a guide, a "spiritus rector of daily life" (CW 14, par. 777). That Jung took this philosophy to heart can be seen from the many stories about his unusual behavior. You may be familiar with this story about Jung. One day when a visitor unintentionally started a fire in an ashtray during an interview, he rushed over to put the fire out; but Jung told him to stop, because the fire had a meaning, and they needed to discover what it was (Zurich folklore). 


\section{Lorenz}

We know from Jung's theory of psychological types, that not everyone has the capacity for intuition that makes it possible to appreciate synchronistic events. Intuitives are a minority of the population by any count, though often the majority of Jungians, artists, and schizophrenics. We might ask, from an evolutionary point of view, why has such a capacity been useful for survival? Jung and his circle offer two important reasons. One is that experiences of synchronicity and precognition bring can bring with them a sense of healing, meaning, or Fate. Aniela Jaffee suggests that experiences of synchronicity

can bring light into a hard life, illuminate a stretch of the way, and provide great relief. This often happens when the foreknowledge or prophesy is felt to have established a meaning in the sequence of events. People are much more ready to submit to a fate that has meaning than to one that is blind and inscrutable. According to many letters, foreknowledge in itself is felt to relieve anxiety. Possibly in these cases the psyche is prepared for an imminent and painful blow of fate by experiencing it beforehand in the mind; it is a kind of rehearsal. (20)

A second reason is that there are times in history when all conventional wisdom proves inadequate to deal with catastrophic events that have ruptured expectations. When the plague strikes, a civil war breaks out, game suddenly disappears, or commercial airliners are flown intentionally into large office buildings, the known world changes dramatically. Peter Homans, professor of religion and psychology at the University of Chicago, has coined the term "symbolic loss" to refer to a kind of collective trauma in which a whole community loses its sense of cohesion, orientation, and meaning (2000). At times of such loss, an intuitive has the capacity to build a bridge, according to Aniela Jaffe, "between the known and the unknown, the everyday event and the timeless." The development of new symbols at such moments can be crucial to well-being and offer a way forward. Contemporary examples of clarifying, healing vision might be Martin Luther King's "I have a dream" speech, architect Maya Lin's Vietnam Veteran's and Civil Rights memorials, or Bishop Tutu's stewardship of the Truth and Reconciliation Commission Hearings in South Africa.

In the fifty year period after Jung and his circle began writing about synchronicity, there was very little scientific research that could be connected in any way to his ideas about acausal order, beside work in quantum physics that suggested that observers seemed to alter the systems they observed. But in the late 1990 's, two streams of thought developed that I believe changed everything. For a long time there had been a nagging doubt on the part of certain biologists that evolutionary theory explained very well why and how species survived or went 
extinct, but it really had no explanation of how new species and new organs formed. They doubted that an eye or ear, let alone a new viable species, could develop out of a random series of gene mutations. There was also a question about the general laws of thermodynamics, which suggest that things in the world gradually lose heat and energy, winding down to a state of entropy. Life, on the contrary seems to be moving in the opposite direction. Ever new and more complex forms of life have emerged over millions of years, inventing ever new ways to gather and transform energy. If we look at the evolution of life over millions of years, we can see a pattern in which life forms become more communicative, more richly creative, more able to process complex information, more spontaneous in their capacities to respond to change. So while some regions of the world are what Ilya Prigogine and Isabelle Stengers have called "closed systems" (1984) in states of equilibrium, in order for life to develop there had to be other regions of the world that were "open systems" where new types of order could spontaneously form. As the computer sciences developed so that very large amounts of data could be processed rapidly, models began to be developed of these different types of information systems.

Jung had already worked out in the 1950's that there had to be another form of order, and he looked for it in one of the places contemporary scientists are studying: the lives of insects. In his article Synchronicity: An Acausal Principle, Jung refers to work on bees being done in the late 1940's that showed that even though bees have no cerebral cortex, they have a complex language through which they communicate direction and distance of feeding locations to each other. Jung deduced from this research, that there is evidence here of a second psychic system operating in the world. He wrote:

Thus we are driven to the conclusion that a nervous substrate like the sympathetic system which is absolutely different from the cerebrospinal system in point of origin and function can evidently produce thoughts and perceptions just as easily as the later. (CW 8, par. 957)

As the science of what is now called Complexity Theory has developed, it has become possible to model four basic types of information systems, based on levels of connectivity, that seem to emerge from the logic of mathematics. Class 1 systems have too few connections to develop creatively and fall into entropy. For example, in colonies of certain types of ants, if there are too few ants, they simply freeze and fail to move or work. Class 2 systems have more connective links, and settle into patterns. In our ant colony, ants are awakened when they are brushed up against by other ants. There have to be enough ants for them to bump into each other. When this happens with enough frequency, the ants will divide into two work groups, one to dig tunnels, and another to clear away debris. They then settle 


\section{Lorenz}

into this pattern for life. Class 3 systems are turbulent and chaotic and no stable patterns ever emerge. In terms of the ant colony in our example, we could imagine the chaos that could emerge if we placed many thousands of diverse insects at the same place. We know that when an ants' nest is disturbed, the ants begin a random and turbulent scatter. Finally, in Class 4 systems, where just the right level of connectivity is reached, beautiful, complex, and coherent structures begin to develop suddenly. We could illustrate such patterns through the evolving underground architectural structure of a well-developed ant or termite nest.

It turned out that these four types of systems can be documented throughout the natural world, in laboratory experiments, in social environments, and in business corporations. A common sense illustration would be the state changes of water. Ice would be a frozen Class 1 system. A lake with gentle wave patterns would be a Class 2 system. A turbulent white-water river would be a Class 3 system. Now if the flow of water is just fast enough, but not too fast in the river, powerful whirlpools will form at random locations, as in the surprising orders of Class 4 systems.

Class 4 systems, according to this still very controversial work, are the origin of life, order, body organs, species, language, imagination, and consciousness. They have exactly the characteristics of synchronistic events: they arise as acausal, non-predictable ordering within the natural world. In this theory, life, psyche, culture, art, ritual and by extension synchronicities, are not random accidents, but a necessary outcome of the inherent mathematical ordering of the world. Jung had a deep intuition that mathematics and synchronicity would be found to be related. $\mathrm{He}$ wrote:

Number helps more than anything else to bring order into the chaos of appearances...Hence it is not such an audacious conclusion after all if we define number psychologically as an archetype of order which has become conscious. (CW 8, par. 870)

While complexity theory has been very useful in helping to conceptualize how synchronicity might connect with the sciences, no model can ever be a final resting point in our understanding. Jung had essentially a post-structuralist view of knowledge:

All knowledge is the result of imposing some kind of order upon the reactions of the psychic system as they flow into our consciousness...It is not a question of asserting anything, but of constructing a model which opens up a promising field of inquiry. A model does not assert that something is so, it simply indicates a particular mode of observation. (CW 8, par. 362) 
If we take seriously the spirit of Jung's work on synchronicity and his suggestion to "dream the dream onward" in every era, it will be in our continuing dialogue with each other, the world, and our communities that we open to what is emergent in the world today. In Jung's final statements on synchronicity, we begin to see a merger of the idea of synchronicity with the idea of a God image. Jung, not long before his death, said this in an interview:

To this day God is the name by which I designate all things which cross my willful path violently and recklessly, all things which upset my subjective views, plans, and intentions and change the course of my life for better or worse. (Edinger 14)

But as we know from his Answer to Job, Jung's notion of God is not an all powerful, all-knowing God, but rather a God we encounter in an incarnation in images in the experience of our own souls. Here, according to Jung,

God is to be carried experientially in the individual...Now, everyone has to carry God. The descent of spirit into matter is complete. (CW 11, par. 153)

Our work over eons, as in the mystical texts of gnosticism, Judaism, and Islam, is to awaken to spirit in the world, and to become bearers of more just and humane relatedness to suffering. In our witness and caring for suffering by ourselves and others, Jung claims, "God becomes conscious in the act of human reflection." Jung talks in several articles about learning to have an "ethical" relationship to the emergent unconscious, to take up the symptoms, emotional life, and images that arise through synchronicities in us and in the world around us as a call, a vocation, and a responsibility. This is, to my mind, a very much needed program for surviving the chaos of the globalized world of the 21 st century. Jung's work on synchronicity opens new ways for us to continue to learn about openness, humility, dialogue, and grace, as we face the challenges of building peaceful environments in a new era. Synchronicity gives us a way to imagine communities as interconnected, filled with untapped spiritual potentials, and called to the work of liberation.

\section{Works Cited}

Bernstein, Jerome. Living in the Borderland: The Evolution of Consciousness and the Challenge of Healing Trauma. London: Routledge, 2005. Print.

Beloff, John. Parapsychology: A Concise History. New York: St Martins Press, 1993.

Cytowic, Richard. Synesthesia: A Union of the Senses. New York: Springer Verlag, 1989. 


\section{Lorenz}

Edinger, Edward and Lawrence Jaffee. Transformation of the God-Image: An Elucidation of Jung's Answer to Job. Chicago: Inner City Books, 1992.

Grof, Stanislav. The Cosmic Game. Albany: SUNY Press, 1998.

Homans, Peter. Jung in Context. Chicago: University of Chicago Press, 1995.

Homans, Peter. ed. Symbolic Loss: The Ambiguity of Mourning and Memory at Century's End. Charlottesville: University Press of Virginia, 2000.

Jaffe, Aniela. Apparitions: An Archetypal Approach to Death, Dreams, and Ghosts. Einsiedeln: Daimon, 1979.

Jung, Carl G. Psychology and Religion: West and East: Collected Works. Vol. 11. Trans. R.F.C. Hull. Princeton: Princeton University Press, 1958.

Jung, Carl G. The Archetypes and the Collective Unconscious: Collected Works. Vol. 9, Part 1. Trans. R.F.C. Hull. Princeton: Princeton University Press, 1959.

Jung, Carl G. The Structure and Dynamics of the Psyche: Collected Works. Vol. 8. Trans. R.F.C. Hull. Princeton: Princeton University Press, 1960.

Jung, Carl G. Mysterium Coniunctionis: Collected Works. Vol. 14. Trans. R.F.C. Hull. Princeton: Princeton University Press, 1963.

Maturana, H.R. and Varela, F.J., The Tree of Life. Boston: Shambhala, 1992.

Perry, John. Roots of Renewal in Myth and Madness: The Meaning of Psychotic Episodes. San Francisco: Jossey-Bass, 1976.

Prigogine, I. and Isabelle Stengers. Order Out of Chaos. New York: Bantam Books, 1984.

Robertson, L.C. and Sagur, N. Perspectives from Cognitive Neuroscience. Oxford: Oxford University Press, 2005.

Shulman (Lorenz), H. Living at the Edge of Chaos: Complex Systems in Psyche and Culture. Eisiedeln: Daimon, 1997.

Young-Eisendrath, Polly and Dawson, Ted, Eds. The Cambridge Companion to Jung. Cambridge: Cambridge University Press, 1997.

von Franz, Marie Louise. Projection and Recollection in Jungian Psychology. La Salle: Open Court, 1980. 